\title{
Escolaridade, emprego e renda: o setor educação mercantil no Paraná em 2006
}

\author{
Mari Aparecida dos Santos ${ }^{*}$ \\ Antonio Carlos Moretto** \\ Rossana Lott Rodrigues $^{* *}$ \\ Ricardo Kureski***
}

\begin{abstract}
RESUMO - A educação é capaz de proporcionar melhorias significativas ao ambiente social e econômico uma vez que, no longo prazo, é meio para o desenvolvimento da capacitação do fator trabalho e, no curto prazo, como setor econômico, interage com outros setores da economia demandando e ofertando bens e serviços. Com enfoque no curto prazo, este estudo objetiva dimensionar a importância econômica do setor educação mercantil no Paraná, em 2006, em termos de emprego e renda. Por meio da Matriz Insumo-Produto (MIP) em conjunto com as informações da Pesquisa Nacional por Amostra de Domicílios (PNAD), os seguintes resultados foram obtidos: i) 58,2\% dos ocupados no setor Educação Mercantil possuíam ensino superior, representando $4,8 \%$ do total de pessoas ocupadas com 12 ou mais anos de estudo no estado; ii) o trabalhador melhor remunerado tinha pós-graduação, com média salarial mensal $104 \%$ maior relativamente à dos trabalhadores com graduação e 165,8\% maior com relação à média salarial dos trabalhadores com ensino médio; iii) o menor diferencial de renda média mensal entre os dois níveis intermediários de escolaridade relativamente aos demais setores da economia paranaense; e iv) dentre os demais setores, o setor educação mercantil seria o sétimo maior gerador de emprego e o segundo maior na geração de renda, no caso do aumento em um milhão de reais em sua demanda final.
\end{abstract}

Palavras-chave: Escolaridade. Emprego. Renda. Insumo-produto.

\section{INTRODUÇÃO}

Os diversos papéis da educação têm sido alvo de discussão por vários autores na literatura contemporânea nacional e internacional, como, por exemplo, Harris (1997), Rolim e Kureski (2007), Hanushek e Woessmann (2008), Kelly, McLellan e McNicoll (2009) e Zaist, Nakabashi e Salvato (2010), dentre outros, visto que existem observações de efeitos benéficos ao ambiente tanto social quanto econômico. Estes benefícios são fenômenos observáveis tanto

\footnotetext{
* Mestre em economia regional pela Universidade Estadual de Londrina. É aluna pesquisadora pela Universidade Estadual de Londrina. Endereço eletrônico: mari.economia@gmail.com.

** Doutor em economia aplicada pela Universidade de São Paulo. É professor da Universidade Estadual de Londrina. Endereço eletrônico: acmoretto@uel.br.

*** Doutora em economia aplicada pela Universidade de São Paulo. É professora da Universidade Estadual de Londrina. Endereço eletrônico: rlott@uel.br.

**** Doutor em economia e política florestal pela Universidade Federal do Paraná. É professor da Pontifícia Universidade Católica do Paraná e técnico do Instituto Paranaense de Desenvolvimento Econômico e Social. Endereço eletrônico: kureski@ipardes.pr.gov.br.
} 
no curto quanto no longo prazo. A educação, como processo de desenvolvimento da capacidade física, intelectual e moral do indivíduo e, por conseguinte, da sociedade, apresenta resultados no longo prazo. Por outro modo, a educação como setor econômico envolve implicações no curto prazo, por englobar grandes organizações que interagem como demandantes de diversos segmentos, os quais também necessitam de insumos produzidos por outros setores, resultando na produção de bens e serviços para atender universidades, faculdades, escolas, pré-escolas e instituições afins, sejam públicas ou mercantis (ROLIM; KURESKI, 2007).

Ademais, os impactos econômicos, no curto prazo, podem ser observados ao tomar a educação como setor. As instituições de ensino compõem o setor educação, o qual promove gastos propulsores de impactos na cadeia produtiva, ou seja, afetam a produção dos fornecedores que, por sua vez, demandam insumos de diversos setores (MILLER; BLAIR, 2009).

Considerando essas ligações intersetoriais, as quais resultam na produção de bens e serviços, com foco no curto prazo, a presente pesquisa objetivou verificar a importância econômica do setor educação mercantil paranaense, no curto prazo, em termos de geração de emprego e de renda em 2006.

Este estudo está dividido em cinco seções, incluindo esta introdução. A segunda contempla uma síntese sobre a evolução quantitativa da educação mercantil no Paraná. Na terceira seção são sintetizados os procedimentos metodológicos enquanto as seções seguintes, quarta e quinta, apresentam os resultados e considerações finais, respectivamente.

\section{SÍNTESE DA EVOLUÇÃO EDUCACIONAL MERCANTIL NO PARANÁ}

No Paraná, o número de estabelecimentos de ensino privado cresceu consideravelmente na década de 1990. É importante observar que a variação do crescimento, em número, das instituições municipais, estaduais e federais de ensino foi superada pela da rede de educação mercantil, ou particular, no período entre 1996 e 2006, embora houvesse estabelecimentos públicos de ensino em maior quantidade, como se verifica na Tabela 1. Ao longo da década observada, notou-se que as variações no número de estabelecimentos de ensino foram maiores no primeiro quadriênio, com aumento de $47,2 \%$ no número de estabelecimentos da rede particular e queda do da rede pública em 18,2\%. Ao final do período, constatou-se aumento em $68,6 \%$ no número de estabelecimentos de educação mercantil, passando de 1.224 para 2.064, e redução de 26,8\% no número de estabelecimentos públicos, de 9.876 para 7.228 (Tabela 1).

Michelotto, Zainko e Andrich (2006), estudando a educação no Paraná, enfatizaram que a expansão maior se deu no ensino superior no período entre 1991 e 2004, sendo o crescimento maior nas instituições não universitárias, como os centros universitários e de educação 
tecnológica, faculdades integradas e de tecnologia, em que a variação chegou a 213,3\% no mesmo período.

TABELA 1 - ESTABELECIMENTOS DE ENSINO, PARANÁ, 1996 - 2006

\begin{tabular}{|c|c|c|c|c|c|c|c|}
\hline Estabelecimentos de Ensino & 1996 & $\Delta \%$ & 2000 & $\Delta \%$ & 2004 & $\Delta \%$ & 2006 \\
\hline Rede municipal, estadual e federal & 9.876 & $-18,2$ & 8.080 & $-8,8$ & 7.373 & $-2,0$ & 7.228 \\
\hline Rede particular & 1.224 & 47,2 & 1.802 & 9,7 & 1.976 & 4,5 & 2.064 \\
\hline Total & 11.100 & $-11,0$ & 9.882 & $-5,4$ & 9.349 & $-0,6$ & 9.292 \\
\hline
\end{tabular}

FONTE: IPARDES (2010).

\section{METODOLOGIA}

Para atender ao objetivo proposto, utilizou-se a análise insumo-produto. $\mathrm{O}$ modelo ${ }^{1}$ segue a forma geral dada pela Equação 1:

$$
X=Y(I-A)^{-1}
$$

em que, $X$ é o vetor do valor bruto da produção total por setor, de ordem ( $n \times 1)$; $I$ é a matriz identidade de ordem $n \times n, A$ é a matriz de coeficientes técnicos de insumos diretos, de ordem $(n \times n), \operatorname{logo}(I-A)^{-1}$ representa a matriz de coeficientes técnicos de insumos diretos e indiretos, ou matriz inversa de Leontief, denominada matriz $B$, de ordem $(n \times n)$; e $Y$ é o vetor de demanda final total por setor, de ordem ( $n$ x 1), variável exógena ao sistema (MILLER; BLAIR, 2009).

Assim, a partir da matriz inversa de Leontief e dos coeficientes diretos de emprego e renda, é possível estimar, para cada setor da economia, o quanto seria gerado dessas variáveis, direta e indiretamente, para cada variação de um milhão de reais na demanda final, de acordo com a Equação 2:

$$
G V_{j}=\sum_{i=1}^{n} b_{i j} \nu_{i}
$$

em que $G V_{j}$ é o gerador que mede o impacto total, direto e indireto, sobre a variável em questão; $b_{i j}$ é o $\ddot{j}$-ésimo elemento da matriz inversa de Leontief e $v_{i j}$ é o coeficiente direto da variável em questão, no caso desta pesquisa, o emprego e a renda.

\subsection{DADOS E SEU TRATAMENTO}

Para a realização deste trabalho utilizou-se a matriz insumo-produto (MIP) do Paraná para o ano de 2006, construída por Kureski (2006), por ser a matriz mais recente disponibilizada para o estado.

1 Para características do modelo, ver Feijó et al. (2003). 
Conjuntamente com a matriz insumo-produto, fez-se uso das informações contidas na Pesquisa Nacional por Amostra de Domicílios (PNAD) de 2006 (IBGE, 2006), com a finalidade de estratificar o emprego e a renda ${ }^{2}$, contidos na MIP, em seis grupos conforme o perfil educacional das pessoas ocupadas: i) sem instrução, o qual compreende as pessoas ocupadas com menos de um ano de escolaridade; ii) fundamental, agrupamento de trabalhadores com escolaridade entre um e oito anos ${ }^{3}$; iii) médio, compreendido por trabalhadores com 9 a 11 anos de estudo; iv) graduação, agrupamento dos trabalhadores com escolaridade entre 12 e 14 anos de estudo; v) pós-graduação, composto dos empregados com 15 anos ou mais de estudo; e vi) não definido, agrupamento dos empregados que não identificaram o seu nível escolar.

O setor educação mercantil, foco desse estudo, de acordo com a Comissão Nacional de Classificação-CONCLA (IBGE, 2010), compreende o conjunto de todas as unidades que realizam atividades de ensino privado, em qualquer nível e para qualquer finalidade, na forma presencial ou à distância, por meio de rádio, televisão, correspondência ou outro meio de comunicação.

\section{RESULTADOS E DISCUSSÃO}

A distribuição da ocupação no Paraná e no setor educação mercantil, por nível de escolaridade, em 2006, é apresentada na Tabela 2. De acordo com IPARDES (2006), os empre$\operatorname{gados}^{4}$ no Paraná totalizavam 5.614.927 pessoas, representando $54,7 \%$ da população total do estado no ano em foco, estimada em 10.271.684.

Observa-se que, do total de pessoas ocupadas, 68.846 compunham o setor educação mercantil enquanto os demais trabalhadores, 5.546.081, alocavam-se em outros setores de atividade econômica do Paraná. Ao estratificar a ocupação estadual por nível escolar no estado do Paraná, verificou-se a predominância de trabalhadores com escolaridade entre um a oito anos de estudo, ou seja, 43,4\% dos empregados possuíam o ensino fundamental. O restante dos empregados distribuía-se em 36,5\% com nove a onze anos de estudo, 8\% com quinze anos ou mais de estudo, 6,2\% classificados com doze a quatorze anos de escolaridade, 4,7\% sem instrução, ou seja, com menos de um ano de estudo e 1,1\% das pessoas ocupadas não declararam sua

2 A renda, neste estudo, refere-se à remuneração do trabalho, ou seja, salários acrescidos de contribuições sociais efetivas, como Previdência Oficial/FGTS e Previdência Privada.

3 A partir do ano de 2006, com a Lei $n^{\circ}$ 11.274, de 6 de fevereiro de 2006, o ensino fundamental passou a ter, obrigatoriamente, duração mínima de nove anos, revogando a Lei n ${ }^{\circ} 11.114$, de 2005, art. 32, em que constava o ensino fundamental com duração mínima de oito anos (BRASIL, 2006a).

4 Para empregados serão usados como sinônimos população empregada, população ocupada, trabalhadores e pessoas ocupadas. 
escolaridade, formando o grupo não definido ${ }^{5}$ (Tabela 2).

TABELA 2 - DISTRIBUIÇÃO DA OCUPAÇÃO NO PARANÁ E NO SETOR EDUCAÇÃO MERCANTIL, POR NÍVEL DE ESCOLARIDADE, PARANÁ - 2006

\begin{tabular}{|c|c|c|c|c|c|c|c|}
\hline \multirow{3}{*}{ Variável } & \multicolumn{6}{|c|}{ Distribuição da ocupação por nível de escolaridade } & \multirow{3}{*}{ Total } \\
\hline & \multirow{2}{*}{$\begin{array}{c}\text { Sem } \\
\text { instrução }\end{array}$} & Fund. & Médio & Grad. & Pós & \multirow{2}{*}{$\begin{array}{c}\text { Não } \\
\text { definido }\end{array}$} & \\
\hline & & 1 a 8 & 9 a 11 & 12 a 14 & 15 ou + & & \\
\hline Educação mercantil & 509 & 11.050 & 16.664 & 15.647 & 24.467 & 509 & 68.846 \\
\hline$\%$ & 0,7 & 16,1 & 24,2 & 22,7 & 35,5 & 0,7 & 100,0 \\
\hline Paraná & 262.432 & 2.409 .433 & 2.022 .615 & 345.226 & 446.018 & 60.358 & 5.546 .081 \\
\hline$\%$ & 4,7 & 43,4 & 36,5 & 6,2 & 8,0 & 1,1 & 100,0 \\
\hline
\end{tabular}

FONTE: Dados da pesquisa.

Ao comparar o perfil escolar dos empregados do Paraná com o perfil escolar do setor educação mercantil observou-se nesse último a predominância dos empregados com pós-graduação, 35,5\%, seguidos dos que possuíam ensino médio, 24,2\% e graduação, 22,7\%. Logicamente, a detenção de mão de obra com mais alto nível de escolaridade é característica peculiar do segmento educacional, porquanto, o número de trabalhadores graduados (15.647) e pósgraduados (24.467) do setor educação mercantil representava 4,8\% do total de ocupados com ensino superior ${ }^{6}$ em todos os setores do estado, 831.358 (Tabela 2).

No que se refere à distribuição da renda, ou remuneração, por nível de escolaridade, no Paraná em 2006 (Tabela 3), verificou-se que 37,5\% do total foi direcionado ao grupo com ensino superior, sendo $\mathrm{R}$ \$ 6.143,26 milhões aos graduados e $\mathrm{R} \$ 14.445,36$ milhões aos pós-graduados, os quais representavam apenas $6,2 \%$ e $8 \%$ da ocupação, respectivamente.

TABELA 3 - DISTRIBUIÇÃO DA REMUNERAÇÃO NO PARANÁ E NO SETOR EDUCAÇÃO MERCANTIL, POR NÍVEL DE ESCOLARIDADE, PARANÁ, 2006

\begin{tabular}{|c|c|c|c|c|c|c|c|}
\hline \multirow{3}{*}{ Variável } & \multicolumn{6}{|c|}{ Distribuição da remuneração por nível de escolaridade } & \multirow{3}{*}{ Total } \\
\hline & \multirow{2}{*}{$\begin{array}{c}\text { Sem } \\
\text { instrução }\end{array}$} & Fund. & Médio & Grad. & Pós & \multirow{2}{*}{$\begin{array}{c}\text { Não } \\
\text { definido }\end{array}$} & \\
\hline & & 1 a 8 & 9 a 11 & 12 a 14 & 15 ou + & & \\
\hline Educação mercantil(1) & 1,02 & 83,42 & 138,65 & 169,59 & 541,16 & 3,41 & 937,24 \\
\hline$\%$ & 0,1 & 8,9 & 14,8 & 18,1 & 57,7 & 0,4 & 100,0 \\
\hline Paraná(2) & $1.005,46$ & $13.884,04$ & $19.013,59$ & $6.143,26$ & $14.445,36$ & 401,35 & $54.893,06$ \\
\hline$\%$ & 1,8 & 25,3 & 34,6 & 11,2 & 26,3 & 0,7 & 100,0 \\
\hline
\end{tabular}

FONTE: Dados da pesquisa.

NOTA: (1) e (2) valores correntes em milhões de reais.

Ainda conforme apresentado na Tabela 3, o setor educação mercantil direcionou aos trabalhadores com doze ou mais anos de estudo $75,8 \%$ de sua renda, percentual ainda maior do que o observado no conjunto dos demais setores do Paraná. Portanto, verificou-se a supremacia dos trabalhadores com maior nível de escolaridade na detenção de renda deste setor.

É interessante observar a razão da remuneração pelo número de trabalhadores em 5 É importante ressaltar que, por apresentar pouca representatividade perante a amostra, o grupo não definido foi omitido da análise dos resultados.

6 Ensino superior é composto pela graduação e pós-graduação. 
cada grupo, por nível de escolaridade. O resultado deste rateio é a renda média mensal que elucida a tendência observada pelos estudos destacados anteriormente. De acordo com a Tabela 4, a remuneração média mensal do trabalhador cresceu progressivamente à medida que se elevou seu nível escolar. Essa relação pôde ser observada na renda média mensal do trabalhador tanto no setor educação mercantil quanto no Paraná.

TABELA 4 - REMUNERAÇÃO MÉDIA MENSAL NO PARANÁ E NO SETOR EDUCAÇÃO MERCANTIL, POR NÍVEL DE ESCOLARIDADE, PARANÁ - 2006

\begin{tabular}{|c|c|c|c|c|c|c|c|c|}
\hline \multirow{3}{*}{\multicolumn{2}{|c|}{ Variável }} & \multicolumn{6}{|c|}{ Distribuição da remuneração por nível de escolaridade } & \multirow{3}{*}{ Total } \\
\hline & & \multirow{2}{*}{\begin{tabular}{|c|} 
Sem \\
instrução
\end{tabular}} & Fund. & Médio & Grad. & Pós & \multirow{2}{*}{$\begin{array}{c}\text { Não } \\
\text { definido }\end{array}$} & \\
\hline & & & 1 a 8 & 9 a 11 & 12 a 14 & 15 ou + & & \\
\hline \multirow{4}{*}{$\begin{array}{l}\text { Educação } \\
\text { mercantil }\end{array}$} & Ren & 1,02 & 83,42 & 138,65 & 169,59 & 541,16 & 3,41 & 24 \\
\hline & Ocu & 509 & 11.050 & 64 & 47 & 24.647 & 509 & 46 \\
\hline & Reno & 166,99 & 629,11 & ,36 & 903,21 & $1.843,16$ & 558,28 & 1,1 \\
\hline & Ren & $1.005,46$ & $3.884,04$ & $19.013,59$ & $6.143,26$ & $14.445,36$ & 401,35 & 06 \\
\hline \multirow[t]{2}{*}{ Paraná } & Ocup & 262.432 & 2.409 .433 & 2.022 .615 & 345.226 & 446.018 & 60.358 & 5.546 .081 \\
\hline & Renda média mensal(3) & 319,28 & 480,20 & 787,37 & $1.482,91$ & $2.698,95$ & 554,12 & 824,80 \\
\hline
\end{tabular}

FONTE: Dados da pesquisa.

NOTA: (1) valores correntes em milhões de reais no ano de 2006 (dados da Tabela 3); (2) ocupação no ano de 2006 (dados da Tabela 2); (3) valores correntes em reais.

No que se refere à ocupação do setor educação mercantil (Tabela 4), em todos os níveis de escolaridade, exceto no fundamental, esta obteve média salarial inferior à daqueles ocupados em outros setores do Paraná, o que significa que existem setores, ou profissões, melhor remunerados relativamente ao setor foco desse estudo, em que pese o mesmo nível de escolaridade.

Outra constatação importante para o setor educação mercantil foi o menor diferencial de renda média mensal entre os dois níveis intermediários de escolaridade relativamente aos demais setores da economia paranaense em 2006. Entre o nível fundamental e médio a diferença percentual foi de 276,7, bem superior à observada para os demais setores do estado (50,4\%). No caso da renda média do trabalhador com ensino médio o diferencial foi de 10,2\% maior do que a renda do nível anterior, contra $63,1 \%$ nos demais setores, enquanto a remuneração média mensal dos trabalhadores do grupo graduação apresentou variação de 30,3\% comparada ao grupo anterior, inferior aos $89,3 \%$ para os demais setores. O trabalho melhor remunerado foi o dotado de escolaridade equivalente à pós-graduação, com média salarial 104\% maior relativamente à dos trabalhadores com graduação, contra $82 \%$ para os outros setores, e 165,8\% maior com relação à média salarial dos trabalhadores com ensino médio. Para este último caso, o diferencial foi de 244,5\% para os demais setores da economia estadual (Tabela 4).

Ressalta-se que, além da qualificação formal, fatores como cor, gênero, especialização, tempo de serviço, horas trabalhadas etc., podem influenciar a renda do trabalhador e seu dife- 
rencial interníveis de escolaridade. No caso específico do setor educação mercantil, parece-nos que a maior oferta de profissionais nos dois níveis intermediários de escolaridade em 2006 e o valor que o mercado atribui a eles poderiam ser algumas das razões para o menor diferencial de renda média mensal relativamente aos demais setores da economia paranaense.

No entanto, o resultado geral apresenta um panorama condizente com outros estudos, como os de Barros e Mendonça (1997) e Zaist, Nakabashi e Salvato (2010), que confirmam a escolaridade como fator preponderante na determinação da renda, por influir na produtividade do fator trabalho.

Considerando o comportamento do emprego e da renda média dos grupos mais qualificados, empregados tanto no setor educação mercantil quanto nos outros setores da economia estadual, infere-se que estes são dotados de importante capacidade para impactar a demanda final dos outros setores da economia estadual.

TABELA 5 - SELEÇÃO DOS DEZ SETORES COM MAIOR GERAÇÃO DE EMPREGO, POR ESCOLARIDADE, PARANÁ - 2006

\begin{tabular}{|c|c|c|c|c|c|c|c|}
\hline \multirow{3}{*}{ Ordem } & \multirow{3}{*}{ Setor } & \multicolumn{5}{|c|}{ Geração de emprego por nível de escolaridade } & \multirow{3}{*}{ Total } \\
\hline & & \multirow{2}{*}{$\begin{array}{c}\text { Sem } \\
\text { instrução }\end{array}$} & \multirow{2}{*}{$\begin{array}{l}\text { de empr } \\
\text { Fund. } \\
1 \text { a } 8\end{array}$} & \multirow{2}{*}{$\begin{array}{l}\text { Médio } \\
9 \text { a } 11\end{array}$} & \multirow{2}{*}{$\frac{\text { Grad. }}{12 \text { a } 14}$} & \multirow{2}{*}{$\frac{\text { Pós }}{15 \text { ou }+}$} & \\
\hline & & & & & & & \\
\hline $2^{\circ}$ & Metal. metais não ferrosos & 2 & 29 & 34 & 4 & & 71 \\
\hline $3^{\circ}$ & Extrativa mineral & 1 & 27 & 24 & 0 & & 61 \\
\hline $4^{\circ}$ & Agricultura, silv, expl. florestal & 11 & 39 & 8 & 1 & & 60 \\
\hline $6^{\circ}$ & Serviços de alojamento e alim. & 1 & 23 & 21 & 1 & & 49 \\
\hline $7^{\circ}$ & Educação mercantil & 1 & 10 & 13 & 10 & 1 & 48 \\
\hline $8^{\circ}$ & Comércio e serv. de manutenção & 1 & 16 & 24 & 4 & & 47 \\
\hline $9^{\circ}$ & Serviços às empresas & 1 & 12 & 20 & 6 & & 44 \\
\hline $10^{\circ}$ & Construção civil & 2 & 29 & 9 & 1 & & 43 \\
\hline
\end{tabular}

FONTE: Dados da pesquisa.

Assim, como mostrado na Tabela 5, caso houvesse um aumento de um milhão de reais na demanda final do setor educação mercantil, supostamente, proveniente da criação de uma nova instituição ou da expansão das preexistentes, a geração de emprego, direta e indireta no Paraná, em 2006, lograria o total de 48 empregos. A capacidade de gerar empregos colocou o setor educação mercantil em sétimo lugar, dentre os dez setores de maior geração de empregos no estado.

No setor educação mercantil, a maior parte dos empregos gerados, 29,2\%, beneficiaria trabalhadores com escolaridade igual ou superior a 15 anos de estudo. Os trabalhadores com escolaridade entre 9 e 11 anos de estudo deteriam 27,1\% dos empregos. Por sua vez, os trabalhadores com 1 a 8 anos de estudo e os que possuíssem entre 12 e 14 anos de escolaridade responderiam, cada grupo, por 20,8\% dos empregos. Em contrapartida, o menos favorecido 
seria o grupo dos trabalhadores sem instrução escolar, obtendo apenas $2,1 \%$ dos empregos gerados (Tabela 5).

Conforme a Tabela 6, a geração de renda, direta e indireta, gerada pelo aumento de um milhão de reais na demanda final do setor educação mercantil, o colocaria em segundo lugar no ranking dos dez setores de maior geração de renda no estado. Os trabalhadores com escolaridade equivalente a pós-graduação deteriam 53,1\% da renda gerada, enquanto, 17,9\% e 17,4\% da renda estariam direcionados à mão de obra com ensino médio e graduação, respectivamente. A menor parcela seria canalizada para empregados com ensino fundamental, 11\%, e para aqueles sem instrução, $0,3 \%$.

TABELA 6 - SELEÇÃO DOS DEZ SETORES COM MAIOR GERAÇÃO DE RENDA, POR ESCOLARIDADE, PARANÁ - 2006 - EM MIL REAIS

\begin{tabular}{|c|c|c|c|c|c|c|c|}
\hline \multirow{3}{*}{ Ordem } & \multirow{3}{*}{ Setor } & \multicolumn{5}{|c|}{ Geração de renda por nível de escolaridade } & \multirow{3}{*}{ Total } \\
\hline & & \multirow{2}{*}{$\begin{array}{c}\text { Sem } \\
\text { instruçãoo }\end{array}$} & \multirow{2}{*}{$\begin{array}{l}\text { Fund. } \\
1 \text { a } 8\end{array}$} & \multirow{2}{*}{$\begin{array}{l}\text { por nive } \\
\text { Médio } \\
9 \text { a } 11\end{array}$} & \multirow{2}{*}{$\begin{array}{l}\text { Grad. } \\
12 \text { a } 14\end{array}$} & \multirow{2}{*}{$\begin{array}{c}\text { Pós } \\
15 \text { ou }+\end{array}$} & \\
\hline & & & & & & & \\
\hline $1^{\circ}$ & Administração pública & 5,44 & 65,49 & 161,28 & 76,65 & 326,97 & 640,00 \\
\hline $2^{\circ}$ & Educação mercantil & 1,53 & 66,17 & 108,14 & 104,65 & 319,79 & 602,61 \\
\hline $3^{\circ}$ & Outros serviços & 21,25 & 239,03 & 154,84 & 37,37 & 50,70 & 510,55 \\
\hline $4^{\circ}$ & Serviços às empresas & 3,18 & 68,04 & 151,04 & 67,30 & 93,41 & 384,25 \\
\hline $5^{\circ}$ & Saúde mercantil & 2,87 & 71,62 & 152,44 & 43,34 & 107,77 & 383,43 \\
\hline $6^{\circ}$ & Comércio e serv. de manutenção & 3,41 & 100,48 & 180,64 & 38,10 & 47,71 & 372,11 \\
\hline $7^{\circ}$ & Outros equip. de transporte & 0,76 & 29,58 & 251,15 & 31,39 & 16,58 & 366,71 \\
\hline $8^{\circ}$ & Mat. eletrôn. e eq. de comunic. & 0,99 & 20,81 & 74,88 & 88,21 & 152,16 & 342,88 \\
\hline $9^{\circ}$ & Intermediação financ. e seguros & 2,87 & 18,60 & 68,15 & 56,28 & 190,24 & 336,80 \\
\hline $10^{\circ}$ & Transporte, armaz. e correio & 4,46 & 113,47 & 107,74 & 24,94 & 35,73 & 290,59 \\
\hline
\end{tabular}

FONTE: Dados da pesquisa.

Pode-se concluir que, além das externalidades sociais geradas no longo prazo, o setor educação mercantil possui grande potencial, relativamente aos demais setores produtivos paranaenses, para influir, no curto prazo, na economia local, via emprego e renda.

\section{CONSIDERAÇÕES FINAIS}

Esta pesquisa se propôs a analisar a importância econômica do setor educação mercantil, em termos de emprego e renda. Para isto foi utilizada a Matriz Insumo-Produto do Paraná de 2006, conjuntamente com informações da Pesquisa Nacional por Amostra de Domicílios (PNAD).

O setor educação mercantil foi responsável por 1,2\% da ocupação total do estado, com, aproximadamente, 69 mil empregados. Esse setor respondeu pelo dispêndio de 1,7\% da renda total do estado com o fator trabalho, movimentando R\$937 milhões, no ano de 2006. Considerando o perfil escolar da ocupação, mostrou-se forte demandante de mão de obra qualificada, com 58,3\% dos trabalhadores com 12 anos ou mais anos de escolaridade. Esses 
trabalhadores representaram 4,8\% do total de empregados com ensino superior no estado, os quais se mostraram dotados de importante potencial para impactar a demanda final dos demais setores da economia paranaense, por serem melhor remunerados quando comparados àqueles com menor escolaridade.

No que se refere à geração de emprego e renda, caso houvesse aumento em um milhão de reais na sua demanda final, o setor educação mercantil seria o sétimo maior gerador de emprego e o segundo maior gerador de renda.

Notadamente, o setor educação mercantil favoreceria, preponderantemente, trabalhadores com escolaridade igual ou superior a 15 anos de estudo. Em contrapartida, seria mínimo o número de postos de trabalho e remuneração voltados às pessoas sem instrução. Tal aspecto confirma a tendência observada em estudos relacionados nesta pesquisa, em que as oportunidades, bem como a remuneração, são melhores para os indivíduos com maior nível escolar, embora existam outros fatores passíveis que podem influenciar esta relação.

Os benefícios apontados nessa pesquisa justificariam a implementações de políticas públicas voltadas ao setor educação mercantil e, intuitivamente, ao setor educação pública, uma vez que a elevação da média educacional da população paranaense e, por conseguinte, a ampliação dos fluxos intersetoriais dentro do estado, contribuiria com a dinamização das relações de produção e com o ambiente socioeconômico, no curto e longo prazo.

Existem vários aspectos que poderiam ser explorados dentro do tema enfocado nesta pesquisa, o que demonstra a necessidade de estudos futuros. Como sugestão recomenda-se a realização da análise do setor educação pública que, aliado ao setor educação mercantil, permitiria melhor dimensionamento da importância da educação na economia paranaense.

\section{REFERÊNCIAS}

BARROS, R. P.; MENDONÇA, R. Investimentos em educação e desenvolvimento econômico. Rio de Janeiro: IPEA, 1997. p. 525.

BRASIL. Lei n ${ }^{\circ} 11.274$, de 6 de fevereiro de 2006. Diário Oficial [da] República Federativa do Brasil, Brasília, DF, 6 fev. $2006 a$.

BRASIL. Lei no 11.321, de 7 de julho de 2006. Diário Oficial [da] República Federativa do Brasil, Brasília, DF, 7 jul. 2006b.

FEIJÓ, C. A. et al. A contabilidade social: o novo sistema de contas nacionais do Brasil. Rio de Janeiro: Elsevier, 2003.

HANUSHEK, E. A.; WOESSMANN, L. The role of cognitive skills in economic development. Journal of Economic Literature, Nashville, v. 46, n. 3, p. 607-668, 2008.

HARRIS, R. I. D. The impact of the university of Portsmouth on the local economy. Urban studies, Dumfries, v. 34, n. 4, p. 605-626, Apr. 1997. 
INSTITUTO BRASILEIRO DE GEOGRAFIA E ESTATÍSTICA. Pesquisa nacional por amostra de domicílios. Rio de Janeiro: IBGE, 2006. 1 CD-ROM.

INSTITUTO BRASILEIRO DE GEOGRAFIA E ESTATÍSTICA. CONCLA-Comissão Nacional de Classificação. Rio de Janeiro: IBGE, 2010. Disponível em: <http://www.ibge. gov.br/concla/cl_download.php?sl=4>. Acesso em: 15/11/2010.

INSTITUTO PARANAENSE DE DESENVOLVIMENTO ECONÔMICO E SOCIAL(IPARDES), 2010. Disponível em: <http://www.ipardes.gov.br/imp/index.php> Acesso em: 2/6/2010.

KELLY, U.; MCLELLAN, D.; MCNICOLL, I. H. The impact of universities on the UK economy: fourth report. London: Universities UK, 2009.

KURESKI, R. Produto interno bruto: emprego e renda do macrossetor da construção civil paranaense. 2006. Texto não publicado.

MICHELOTTO, R. M.; ZAINKO, M. A.; ANDRICH, E. G. A educação superior no Paraná 1991 - 2004. In: RISTOFF, D.; GIOLO, J. Educação superior brasileira: 1991 - 2004. Brasília: Instituto Nacional de Estudos e Pesquisas Educacionais Anísio Teixeira, 2006. p. 21-68.

MILLER, R. E.; BLAIR, P. D. Input-output analysis: foundations and extensions. New York: Cambridge University Press, 2009.

POPULAÇÃO Curitiba. Disponível em: < http://www.ipardes.gov.br/anuario_2006/estrutura.html > Acesso em: 2/6/2010.

ROLIM, C.; KURESKI, R. Impacto econômico de curto prazo das universidades estaduais paranaenses - 2004. Revista Paranaense de Desenvolvimento, Curitiba, v. 112, p. 111-130, jan./jun. 2007.

ZAIST, J. V.; NAKABASHI, L.; SALVATO, M. Retornos privados da escolaridade no Paraná. Revista Economia, Brasília, v. 11, p. 175-198, jan./abr. 2010. 